\title{
Public attitudes towards genetic testing revisited: comparing opinions between 2002 and 2010
}

\author{
Lidewij Henneman $^{\star, 1,2}$, Eric Vermeulen ${ }^{1}$, Carla G van $\mathrm{El}^{1}$, Liesbeth Claassen ${ }^{2}$, Danielle RM Timmermans ${ }^{2}$ \\ and Martina C Cornel ${ }^{1}$
}

Ten years after the Human Genome Project, medicine is still waiting for many of the promised benefits, and experts have tempered their high expectations. Public opinion on genetic testing has generally been favourable but is this still the case? The aim of this study is to compare public experiences, beliefs and expectations concerning genetic testing over the years (2002 vs 2010). A cross-sectional questionnaire survey was conducted using the Dutch Health Care Consumer Panel in 2002 and 2010. Responses to questions in identical wording were compared. In 2002 and 2010, 817 (63\%) and 978 (70\%) members responded, respectively. Awareness and reported use of genetic tests remained stable over time. In 2010, more respondents expected genetic testing to become more widely applied, believed that knowledge about the genetic background of disease helps people live longer, and that testing should be promoted more intensively. In 2010, they were also more interested in their own genetic make-up. On the one hand, the concern that a dichotomy would emerge between people with 'good genes' and 'bad genes' was higher. On the other hand, respondents thought that insurance companies would be less likely to demand a genetic test in order to calculate health insurance premiums. In conclusion, the results suggest that in $\mathbf{8}$ years, expectations of benefits and potential use of genetic testing have been raised among the public, resulting in more positive opinions. Worries on inequity remain, although worries about premium differentiation by insurance companies have decreased.

European Journal of Human Genetics (2013) 21, 793-799; doi:10.1038/ejhg.2012.271; published online 19 December 2012

Keywords: genetic testing; experiences; public opinion; attitudes; expectations; beliefs

\section{INTRODUCTION}

Over the past 10 years, 'Gene discovered for...' was a constantly recurring announcement in public media, signalling both the expanding knowledge about genes as the underlying cause for disease and the possibilities for genetic testing. Owing to the rapid developments in genomics, the number of diseases for which testing is available have increased sharply (www.Genereviews.org), including direct-to-consumer (DTC) through the internet. ${ }^{1}$ More tests are thus becoming available in healthcare and the public sphere. Ten years after the Human Genome Project, however, most of the promised benefits in terms of prevention, diagnosis and treatment of diseases, in particular with regard to complex diseases, have not materialised in medicine. It has been suggested that genomics is frequently hyped, not only by the media, but also as a result of commercialisation and translation pressure by, for example, funding agencies, and publication pressure on scientists themselves. ${ }^{2}$ The scientific community has expressed doubts about the real value of genomics for healthcare, ${ }^{3}$ and physicians feel far from ready to integrate genomic medical applications into their practice. ${ }^{4}$ Little is known about how the rapid genetic developments in the past - characterised as hope, hype and scepticism - have shaped public views on genetics. Understanding people's attitudes and beliefs may help guide communication efforts by exposing misunderstandings, gaps in knowledge and concerns. Moreover, research on attitudes and expectations of genetic information is considered important because of the need to establish genetic services that are accepted by the public and that are in accordance with people's needs. ${ }^{5,6}$

Public opinion on genetics is generally favourable, although it seems to depend on the type of application and what it is used for. Overall, technologies that lead to the detection and treatment of disease are considered valuable. ${ }^{7}$ Moreover, even for diseases with limited clinical utility of testing, for example, psychiatric disorders, it has been shown that the public is highly favourable towards testing. ${ }^{8}$ Attitudes towards genetic testing where there is thus potential for individuals to use the information for their own health benefit or personal utility are generally positive. ${ }^{9,10}$ Conversely, technologies that aim to change 'natural' processes are less accepted., 5,11 This more adverse response has been seen in the case of biotechnologies such as genetically modified (GM) food, ${ }^{7}$ human cloning ${ }^{11,12}$ and gene therapy. ${ }^{11}$

Attitudes towards genetic testing vary with age, gender and educational level. Overall, younger people seem to show a higher interest in genetic testing, ${ }^{13-15}$ and have more positive attitudes. ${ }^{13,16}$ Men seem to have more positive attitudes towards testing, ${ }^{10,13}$ but some studies have indicated that women are more knowledgeable on genetics. ${ }^{17,18}$ Higher levels of genetic knowledge, mostly among those with higher education, are associated with a more favourable attitude towards genetics in some studies, ${ }^{16,19}$ but this association was not found in others. ${ }^{10,13}$ The relationship between knowledge and support of testing seems more complex, because more knowledge may

${ }^{1}$ Section Community Genetics, Department of Clinical Genetics, EMGO Institute for Health and Care Research, VU University Medical Center Amsterdam, Amsterdam, The Netherlands; ${ }^{2}$ Department of Public and Occupational Health, EMGO Institute for Health and Care Research, VU University Medical Center Amsterdam, Amsterdam, The Netherlands

${ }^{*}$ Correspondence: Dr L Henneman, Section Community Genetics, Department of Clinical Genetics, EMGO Institute for Health and Care Research, VU University Medical Center, PO Box 7057, Amsterdam, 1007 MB, The Netherlands. Tel: + 3120 4449815; Fax: + 3120 4448665; E-mail: I.henneman@vumc.nl

Received 16 July 2012; revised 10 October 2012; accepted 13 November 2012; published online 19 December 2012 
translate to a less perceived benefit of testing. ${ }^{5,20,21}$ Moreover, more detailed information on the application of genetic tests may result in more concern and ambivalence. ${ }^{6,8}$

Although changes of attitudes and beliefs towards genetic testing have been studied in patient groups, ${ }^{22}$ as have changes in attitudes concerning biotechnology in general among the public, ${ }^{23}$ studies of attitudinal changes towards genetic testing among the public are relatively scarce. The studies that have been performed include an analysis of the response to only a few questions, ${ }^{24}$ or cover only a short time period. ${ }^{12}$

Our study covers a longer and interesting time period; from 2002 to 2010. The year 2002 marked the hopeful launch of the 'book of life', and it was still expected that genetics would contribute to the understanding, prevention and cure of many diseases. ${ }^{25}$ In 2010, it was 10 years after decoding the human genome. Among professionals, most of the expectations that had previously been raised were now tempered. With the increasing knowledge about genetics and the possibilities of genetic testing to predict disease, accompanied with media attention, public opinion towards genetic testing may have changed and may continue to change as well. The question is whether the general public is less or more positive about genetic testing, and whether more use of genetic tests has actually been made over the years, especially with the increasing attention being paid to DTC genetic testing, ${ }^{1}$ and with genetic screening (eg, neonatal screening, prenatal screening) becoming more widespread. ${ }^{26}$

This study determines in what way experiences with genetic tests, beliefs and expectations towards the availability, use and consequences of genetic testing have changed over time by comparing responses among members of the public in 2010 with responses in $2002 .{ }^{10,18}$

\section{PARTICIPANTS AND METHODS}

\section{Participants and procedure}

The data were gathered using a cross-sectional questionnaire survey conducted among members of a panel (the Dutch Health Care Consumer Panel) that was used in an earlier study in 2002. ${ }^{10,18}$ The Consumer Panel is managed by the Netherlands Institute for Health Services Research (ISO certified) and aims to measure, at a national level, opinions on and knowledge about healthcare and the expectations and experiences concerning healthcare. The total panel consists of approximately 6000 members aged 18 years and above. Every 3 years, one-third of the panel members are renewed. New members of the panel are sampled from the general population. The Dutch Health Care Consumer Panel is registered with the Dutch Data Protection Authority.

Questionnaires were sent to a selection of 1399 members in September 2010. This sample was considered representative of the Dutch population in terms of age and sex. Panel members did not receive a reminder when they did not respond to the initial invitation.

\section{Measures \\ Questions from the 2002 questionnaire were again asked in the same wording. Additional questions were asked on (the governance of) preventive genomics and the role of family history and disease prevention, and these results will be presented elsewhere (Vermeulen, in preparation). Specific questions in this study addressed the following issues:}

Experiences with hereditary diseases and tests. Familiarity with genetic diseases and genetic testing was derived from the responses to the questions (Table 2): do you know anyone with a genetic disorder (self, in family or neighbourhood)? Had you heard or read about genetic testing before receiving this questionnaire (if yes, which genetic test)? Did you, your partner or child/ children ever have a genetic test (if yes, which one)?

Beliefs about genetic testing. Respondents were asked to indicate the extent to which they agreed with seven statements on perceived (personal) benefits of testing and assumed disadvantages of genetic testing (Table 3). The answers were scored on a five-point Likert scale $(1=$ completely disagree to $5=$ completely agree).

Attitude towards the availability and use of genetic tests was assessed using four statements shown in Table 4. The answers were scored on a five-point Likert scale $(1=$ completely disagree to $5=$ completely agree $)$.

Expected consequences of medical genetic developments in the next 10-15 years were assessed using seven statements addressing the impact on society and anticipated use of genetic information (Table 5). The answers were scored on a five-point scale $(1=$ very unlikely to $5=$ very likely $)$

In addition to these questions, participants were asked to fill in their age, sex and highest level of education.

\section{Data analyses}

Descriptive statistics were used to describe the characteristics. Outcomes are presented in three answering categories ((completely) disagree/(very) unlikely $v s$ not disagree, not agree/not unlikely, not likely $v s$ (completely) agree/(very) likely). The data were compared with questionnaire data from the 2002 survey by testing for difference in variance between the groups and controlling for differences of respondent characteristics associated with outcomes between the cohorts using univariate analysis of variance. Differences in cohort characteristic were assessed with $\chi 2$ tests. A $P$-value $<0.05$ was considered to indicate statistical significance. The statistical programme SPSS 15.0 (SPSS Inc. Chicago, IL, USA) for Windows was used for analysis.

\section{RESULTS}

\section{Sample characteristics}

Overall, in 2010 the response rate to the questionnaire was 70\% (978/ 1399), compared with $63 \%(817 / 1308)$ in $2002 .{ }^{18}$ Owing to incomplete questionnaires, 14 and 6 respondents were excluded from the analyses in 2010 and 2002, respectively. Non-responders were more likely to be younger $(P<0.001)$. Table 1 shows the sociodemographic characteristics of the respondents. In 2002, there were more respondents in the youngest age group compared with $2010(P<0.001)$, Mean age of the respondents in 2002 was 53.8 years (range 25-90 years), and in 2010 this was 59.2 years (range 21-91 years). Respondents were less educated in 2002 compared with 2010 $(P<0.001)$. The cohorts did not differ with respect to gender. In the subsequent analyses, the cohorts were controlled for differences in age and education level.

\section{Experiences with genetic diseases and tests}

Familiarity of the respondents with genetic diseases has not changed over the 8-year period. About one-third of the respondents in both years reported that they knew someone with a hereditary disease, and $13 \%$ and $14 \%$ reported that they themselves had a hereditary disease in 2002 and 2010, respectively. The percentage of people having heard of genetic testing and who reported having had a genetic test in both years was about the same (Table 2). Similar types of tests were mentioned in both years, with most respondents referring to cancer genetic tests followed by genetic testing for chromosomal defects (data not shown).

\section{Beliefs about genetic testing}

Respondents' beliefs about genetic testing are shown in Table 3 . Overall, when looking at both years, respondents' beliefs differed depending on their age and education. For example, those with lower education and older respondents more often believed that genetic tests deprive people's freedom to live as they want compared with higher educated (43\% vs 32\%, respectively, $P<0.001)$ and younger respondents ( $41 \%$ vs $29 \%$, respectively, $P=0.014$ ). Lower educated respondents more than higher educated respondents also believed 
that genetic testing is 'tampering with nature' (25\% vs $10 \%$ respectively, $P<0.001$; data not shown).

After controlling for respondent characteristics (age and education), several differences in beliefs were found between responses of the panel respondents in 2002 and 2010. In 2010, respondents were more curious about their genetic make-up $(P=0.001)$, and were more willing to know about diseases they might get in the future compared with $2002(P<0.001)$. There was also an increase in the proportion of respondents ( $43 \%$ in 2002 vs 64\% in 2010) expecting that knowledge about genetic background would help people to live longer $(P<0.001)$. About the same proportion in both years wanted to know the risk of disease in order to prevent disease. Although in 2010, there was no change in the perception that genetic testing does more good than harm $(P=0.083)$, fewer respondents considered genetic testing as 'tampering with nature' $(P<0.001)$.

\section{Attitudes toward the availability and use of genetic tests}

More respondents in 2010 believed that the use of genetic tests should be promoted $(P<0.001)$, although $37 \%$ still believed that this should not be done (Table 4). On average, fewer respondents believed that genetic testing should be offered to all pregnant women $(P=0.043)$. About half of all respondents agreed that more money should be available for the development of genetic tests, and this proportion did not change in the 8 years considered $(P=0.913)$.

Table 1 Characteristics of respondents in 2002 and 2010

\begin{tabular}{lccc}
$2002^{a}$ & 2010 & \\
& $\begin{array}{c}n=811) \\
n(\%)\end{array}$ & $\begin{array}{c}(\mathrm{n}=964) \\
n(\%)\end{array}$ & P-value \\
\hline Gender, female & $465(57)$ & $546(57)$ & 0.767 \\
Age & & & \\
$20-39$ years & $165(20)$ & $82(9)$ & \\
$40-64$ years & $423(52)$ & $539(56)$ & \\
$\geq 65$ years & $223(28)$ & $343(36)$ & \\
& & & \\
Level of educationc & & $179(19)$ & \\
Low & $352(44)$ & $459(49)$ & \\
Medium & $275(34)$ & $307(33)$ & \\
High & $179(22)$ & &
\end{tabular}

Numbers do not add up to the total because of missing values.

aSee references Henneman et al. ${ }^{10,18}$

${ }^{\mathrm{b}} \chi^{2}$ Analyses.

Low = primary school, lower level of secondary school, lower vocational training; medium = higher level of secondary school, intermediate vocational training; high = higher vocational training, university.
Expected consequences of medical genetic developments

Respondents were asked about the expected consequences of the developments in medical genetics in the next 10-15 years. Overall, in comparison with 2002, respondents in 2010 anticipated more use of genetic information (Table 5). They were more convinced that it would be common to have a genetic test $(P=0.003)$, that we would all have a genetic passport $(P=0.008)$, that future employees would have to have a genetic test before being employed $(P<0.001)$ and that all children would be tested at a young age to find out what diseases they would get $(P<0.001)$. The 2010 respondents also expected more frequently that a dichotomy in society would emerge between people with a 'good' genetic predisposition and people with a 'bad' one $(P<0.001)$. However, the expectation that insurers would ask for a genetic test to determine the level of the premium had decreased since $2002(P=0.042)$.

\section{DISCUSSION}

This study compares public attitudes towards genetic testing in 2010 to a comparable study in 2002. Although the reported use and awareness of genetic testing had not changed over time, respondents in 2010 expected genetic testing to become more common and anticipated more use of genetic information when compared with 2002. The 2010 respondents thought more often that knowledge about the genetic background of disease would help people live longer, and were also more curious about their genetic make-up. Although worries about premium differentiation by insurance companies had decreased, more respondents in 2010 worried about an emerging dichotomy as a result of genetic predisposition. Overall, younger respondents and people with higher education seemed to have fewer concerns. The analyses comparing 2002 to 2012 were therefore corrected for age and education.

Singer has shown that from 1990 till 2004, a period when the 'genomic revolution' was just emerging, awareness of genetic testing in the United States was steadily increasing. ${ }^{24}$ Two other longitudinal studies in the Netherlands showed that from 2002 over a period of 2 years $^{22}$ to 3 years ${ }^{12}$ follow-up, attitudes towards genetic testing and genetic knowledge had not changed much, probably due to the short time period. This study shows that although awareness of genetic testing has not increased at 8 years follow-up, that is, no more respondents claimed to have heard about genetic testing, people now expect more use of testing, hold more positive opinions, and fewer respondents believe that genetic testing is 'tampering with nature'.

The results suggest that the public does not share the tempered expectations that are expressed by professionals. ${ }^{3}$ It has been argued that hype in science, as well as for genomics, may lead to a reduction in public trust. ${ }^{2}$ In our study, more than half of the respondents agreed that more money should be made available for the development of genetic tests, and this percentage had not changed

Table 2 Respondents' experiences with genetic diseases and tests (2002 vs 2010)

\begin{tabular}{|c|c|c|c|}
\hline & $\begin{array}{c}2002^{a} \\
(n=811) \\
n(\%)\end{array}$ & $\begin{array}{c}2010 \\
(n=964) \\
n(\%)\end{array}$ & P-value \\
\hline Knows anyone with a genetic disorder (self, in family or neighbourhood) & $279(34)$ & $335(35)$ & 0.716 \\
\hline Has heard or read about genetic testing before receiving this questionnaire & $461(57)$ & $528(55)$ & 0.509 \\
\hline Had a genetic test (self, partner or child(ren)) & $67(8)$ & $96(10)$ & 0.183 \\
\hline
\end{tabular}




\begin{tabular}{|c|c|c|c|c|}
\hline & $\begin{array}{c}2002^{\mathrm{a}} \\
(\mathrm{n}=964)\end{array}$ & $\begin{array}{c}2010 \\
(\mathrm{n}=811)\end{array}$ & & \\
\hline & & & $F(d t)$ & P-value \\
\hline (Completely) disagree, \% & 21 & 25 & & \\
\hline Not agree/not disagree, \% & 27 & 22 & & \\
\hline (Completely) agree, \% & 52 & 53 & & \\
\hline I am curious about my genetic make-up & $2.95(1.26)$ & $3.17(1.26)$ & $11.47(1,1718)$ & 0.001 \\
\hline (Completely) disagree, \% & 36 & 31 & & \\
\hline Not agree/not disagree, \% & 30 & 26 & & \\
\hline (Completely) agree, \% & 34 & 44 & & \\
\hline I do not want to know what kind of diseases I could get in the future & $3.61(1.25)$ & $3.23(1.33)$ & $32.94(1,1715)$ & $<0.001$ \\
\hline Genetic tests deprive people's freedom to live as they want & $3.08(1.26)$ & $3.02(1.20)$ & $0.10(1,1716)$ & 0.747 \\
\hline (Completely) disagree, \% & 31 & 33 & & \\
\hline Not agree/not disagree, \% & 33 & 31 & & \\
\hline (Completely) agree, \% & 36 & 36 & & \\
\hline Knowledge about the genetic background of disease will help people to live longer & $3.32(1.09)$ & $3.70(1.03)$ & $39.91(1,1714)$ & $<0.001$ \\
\hline (Completely) disagree, \% & 20 & 12 & & \\
\hline Not agree/not disagree, \% & 37 & 24 & & \\
\hline (Completely) agree, \% & 43 & 64 & & \\
\hline Genetic testing does more good than harm & $3.01(1.03)$ & $2.90(1.11)$ & $3.01(1,1704)$ & 0.083 \\
\hline (Completely) disagree, \% & 26 & 33 & & \\
\hline
\end{tabular}

All answering scales to statements $1=$ completely disagree to $5=$ completely agree

a See reference Henneman et al. ${ }^{10}$

bSignificant differences between 2002 and 2010 (analysis of covariance with educational level and age as covariates).

compared with 2002, suggesting that the public still supports investments in genetics research. Similar optimistic public attitudes have been found toward nanotechnology, despite increased awareness of the risks, ${ }^{27}$ and in particular toward the application in the screening, diagnosis and treatment of disease ('nanomedicine'). ${ }^{28}$ It has also been shown that in contrast to more controversial biotechnological developments such as animal cloning and GM foods, higher levels of familiarity and engagement with nanotechnology over time significantly reduces worry. ${ }^{29}$

The question remains how attitudes towards genetic testing are formed and changed. Earlier we have shown that people who are familiar with a genetic disease are more likely to support the availability and use of genetic tests. ${ }^{10}$ More knowledge, however, does not automatically lead to more positive attitudes, as more critical reactions have been observed among those with the highest levels of knowledge. ${ }^{20}$ In our study in 2002, no association between respondents' attitudes and genetic knowledge was found, and it was concluded that a negative attitude does not simply reflect a lack of understanding. ${ }^{10}$
Overall, awareness of genetics is considered relatively high. ${ }^{5}$ For example, it has been shown that people are aware that common chronic disorders, such as diabetes, have a multifactorial aetiology. ${ }^{30}$ However, it has also been shown that the public has limited knowledge on how genetic risk factors influence the development of disease in particular in relation to other risk factors. ${ }^{31}$ For example, in 2002, onethird of respondents believed that if a person has a genetic predisposition for a disease, this person will certainly get the disease. ${ }^{18}$ In contrast to our study in 2002, in 2010 genetic knowledge was not assessed. Thus, we do not know whether knowledge has increased over the years in this particular group of respondents, and how it may or may not have influenced public attitudes.

We did not find any increase in the reported use of genetic testing for people themselves or their family members. One explanation may be that although more screening has become available (eg, neonatal, prenatal), these are often not perceived as 'genetic' tests. ${ }^{18}$ Furthermore, most diagnostic tests are still available only to those people identified as having a priori high risk, because of, for example, 


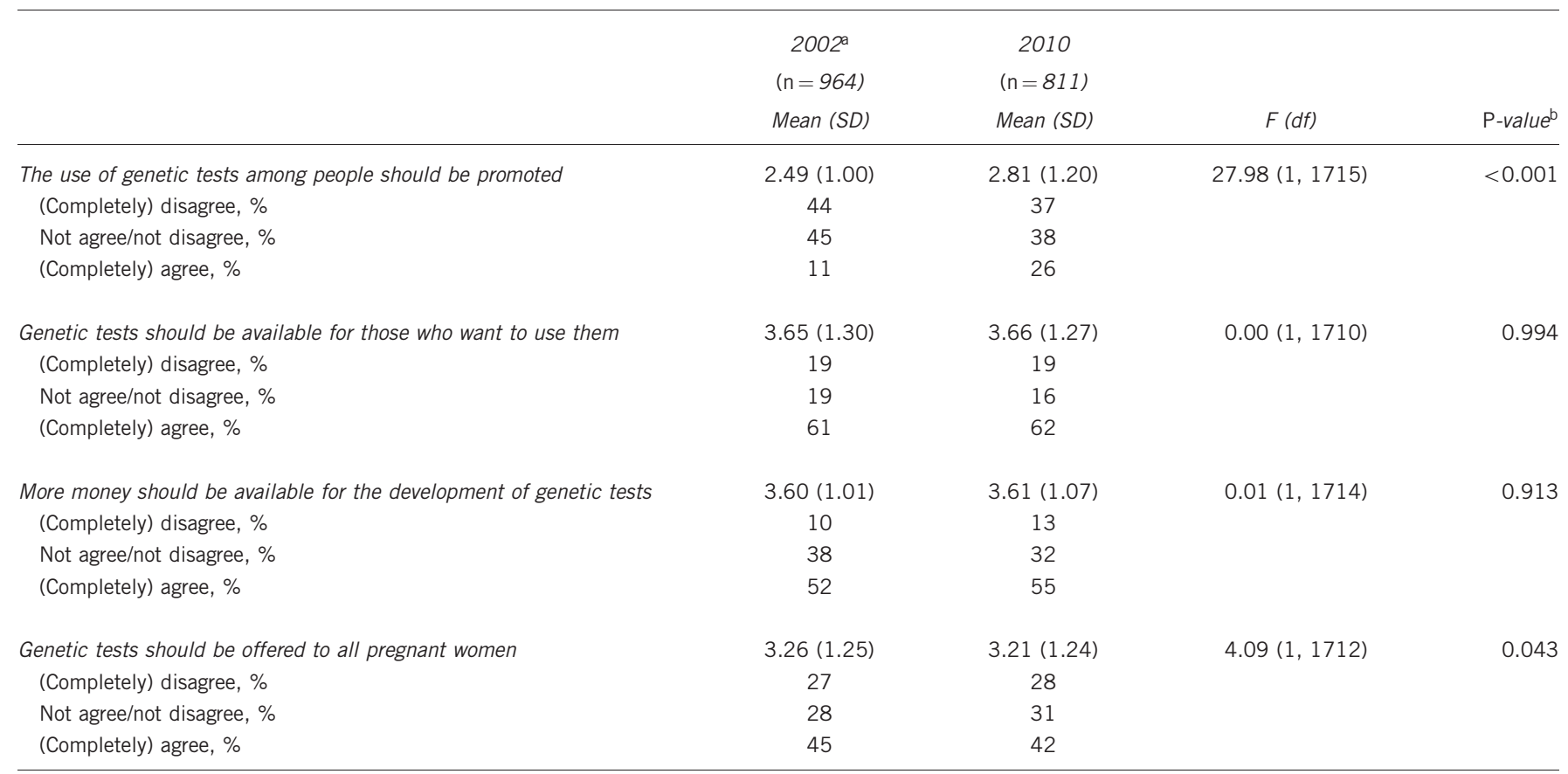

All answering scales to statements $1=$ completely disagree to $5=$ completely agree.

all answering scales to statements

bSignificant differences between 2002 and 2010 (analysis of covariance with educational level and age as covariates).

a positive family history. Finally, public use of DTC genetic testing is still limited. ${ }^{1}$ There is, however, an increasing interest among the public in knowing one's predisposition to disease, as our study also suggested. Interest in genetic testing has been described, in particular also for multifactorial diseases in which the contribution of genes is rather low. ${ }^{14,15,21}$ Increasing use of testing is thus expected, in particular with decreasing costs of testing. ${ }^{14}$ We are now entering a new period in genetics as sequencing becomes cheaper and whole genome sequencing is being used in clinical care. ${ }^{32,33}$ Comparing the changing perspectives may show how the public thinks about genetics in healthcare and under which conditions it could be integrated. The data from this study acknowledge the call for more governmental action, in particular as we see that people not only expect more from genetic testing, they are also more worried about the societal impact in terms of a dichotomy between people with 'good genes' and 'bad genes'. The latter finding may be a reflection of what is taking place on a state level, namely the continuous shift and reform of the Dutch welfare state from collective solidarity towards individual responsibility. ${ }^{34}$

It is noteworthy that worries about premium differentiation by insurance companies as a result of an increase in genetic testing have decreased since 2002. One explanation might be the implementation of a structural healthcare reform in the Netherlands in 2006, whose introduction terminated the dual system of private and public insurance for curative care. ${ }^{35} \mathrm{~A}$ basic healthcare insurance package defined by the government is now mandatory for everyone living in the Netherlands and insurance companies must accept all applicants. Perhaps this makes respondents feel less worried about inequalities in access to health insurance. For life insurance, the experiences of covenants between stakeholders for HIV/AIDS and for familial hypercholesterolemia may have increased trust.

This study has several strengths and limitations. Public attitudes were addressed over a relatively long period of time; 2002-2010. In both years, the data were gathered among the members of one Dutch consumer panel, which can be considered strengths of the study, although all members are periodically replaced. The panel is asked to complete surveys that aim at healthcare-related subjects, which may have attracted those more interested in developments in this field. Therefore, they may possibly be more knowledgeable about healthcare, although this was similar in both years. The composition of the panel of respondents was different for the 2 years; in 2010, panel members were older and higher educated. These two factors (age and education) are known to be confounders and were thus controlled for in the analyses comparing 2002 and 2010. Furthermore, in both years, relatively more younger panel members did not respond to the questionnaire, and ethnic minorities, who may have a different view, ${ }^{5}$ were underrepresented. For some questions in both years, responses were rather divided (not overly positive or negative). It has been shown that public attitudes are sometimes ambiguous, resulting from a coexistence of general support for testing on the one hand, and doubt and opposition for specific aspects of testing on the other hand. ${ }^{36}$ A divided response could also mean lack of interest, lack of acquaintance with the subject or confusion about the question. In particular, those with low level of knowledge may have had difficulty to take a stance. ${ }^{20}$ Moreover, it remains unknown whether respondents interpreted the questions in the same way as in 2002, considering that circumstances have changed. In addition, questions were presented in a different context because also some new questions were added to the questionnaire in 2010. Finally, this study only addresses public attitudes in the Netherlands, and results cannot be seen as being representative for other European countries. The response to certain questions may be influenced by specific changes in Dutch society (eg, insurance practice). Earlier research has also shown that the Netherlands has a relatively positive attitude towards biotechnology including genetic testing, ${ }^{7}$ and it was suggested that this may have to do with relatively high public trust in government, and the media presenting a rather balanced view on biotechnology. ${ }^{37}$ 
Table 5 Expected consequences of genetic developments in the next 10-15 years (2002 vs 2010)

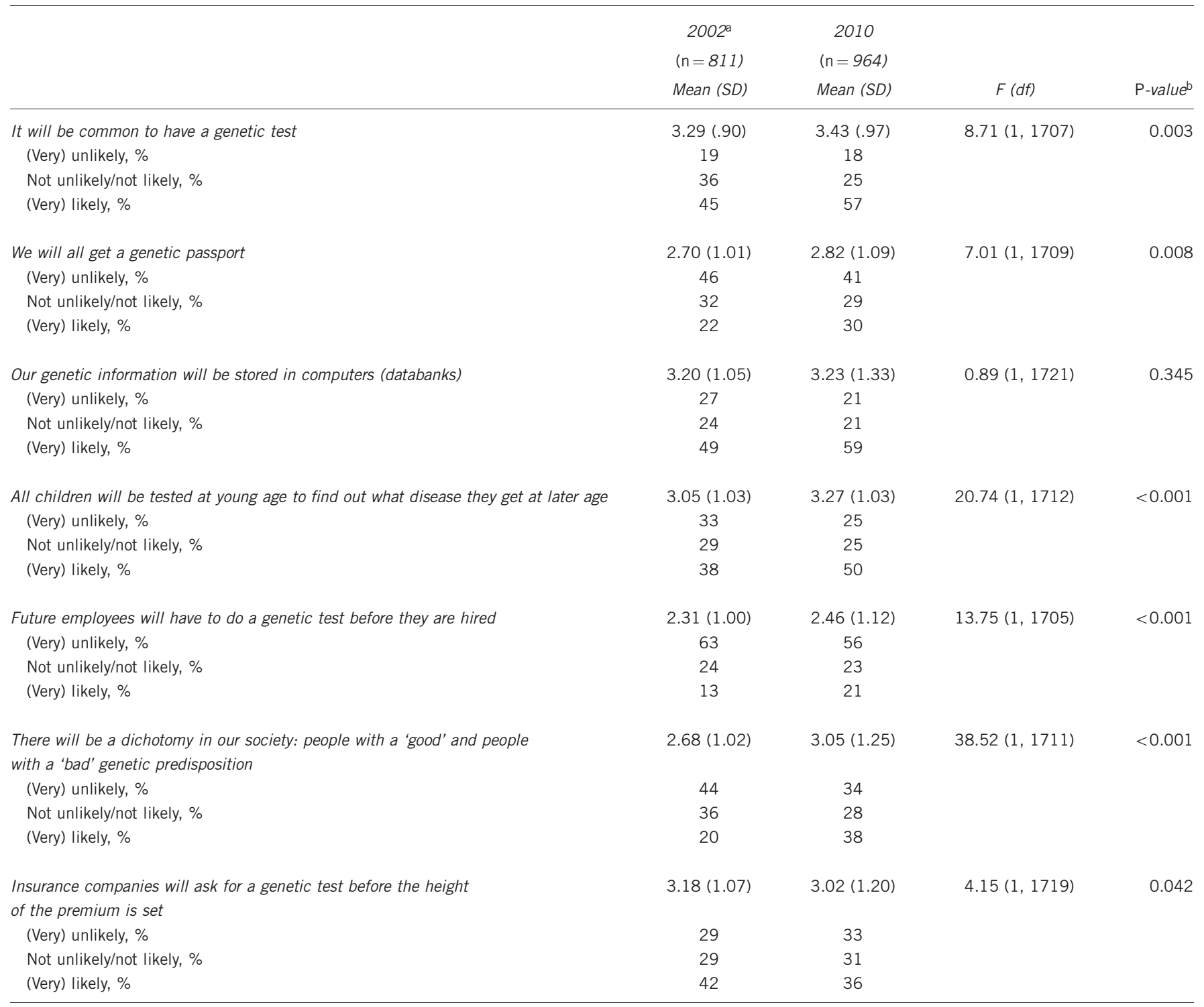

All answering scales to statements $1=$ very unlikely to $5=$ very likely.

aSee reference Henneman et al. ${ }^{18}$

bSignificant differences between 2002 and 2010 (analysis of covariance with educational level and age as covariates).

However, many similarities with global developments are evident, and trends described in this study may thus be seen elsewhere.

In conclusion, this study suggests that although experiences and awareness did not increase over an 8-year time period, the rapid genetic developments resulted in increased expectations among the public and more positive views. The tempered expectations that were observed among experts are not evident among the public. The public expects genetic testing to become even more common and more accepted. The public is aware that genetic testing may potentially be beneficial for them, but worries about downsides, in particular for society, are also expressed. As genetic services are becoming increasingly available and more relevant to mainstream healthcare, these results are of interest to both health care professionals working in the field of genetics, and to non-genetic medical specialists, primary care and community health workers, policy makers and researchers. From these results, we can conclude that advances in genetic testing will probably not meet public opposition. Responsible dialogue with the public regarding the possible societal consequences of genetic testing, such as inequity, as well as promoting policies addressing these potential negative social consequences seems advisable.

\section{CONFLICT OF INTEREST}

The authors declare no conflict of interest.

\section{ACKNOWLEDGEMENTS}

We thank the members of the Dutch Health Care Consumer Panel for completing the questionnaires. The Netherlands Institute for Health Services Research (NIVEL) is acknowledged for project collaboration. The study is part of the research programme of the CSG Centre for Society and the Life Sciences in the Netherlands, and is financially supported by the Netherlands Genomics Initiative. 
1 Borry P, Cornel MC, Howard HC: Where are you going, where have you been: a recent history of the direct-to-consumer genetic testing market. J Community Genet 2010; 1: 101-106.

2 Caulfield T, Condit C: Science and the sources of hype. Public Health Genomics 2012; 15: 209-217.

3 Evans JP, Meslin EM, Marteau TM, Caulfield T: Genomics. Deflating the genomic bubble. Science 2011; 331: 861-862.

4 Houwink EJ, Van Luijk SJ, Henneman L, Van der Vleuten C, Dinant GJ, Cornel MC: Genetic educational needs and the role of genetics in primary care: a focus group study with multiple perspectives. BMC Fam Pract 2011; 12: 5.

5 Condit CM: Public attitudes and beliefs about genetics. Ann Rev Genomics Hum Genet 2010; 11: 339-359.

6 Etchegary H, Cappelli M, Potter B et al: Attitude and knowledge about genetics and genetic testing. Public Health Genomics 2010; 13: 80-88.

7 Gaskell G, Allum N, Bauer M et al: Biotechnology and the European public. Nat Biotechnol 2000; 18: 935-938.

8 Wilde A, Meiser B, Mitchell PB, Schofield PR: Public interest in predictive genetic testing, including direct-to-consumer testing, for susceptibility to major depression: preliminary findings. Eur J Hum Genet 2010; 18: 47-51.

9 Laegsgaard MM, Mors 0: Psychiatric genetic testing: attitudes and intentions among future users and providers. Am J Med Genet B Neuropsychiatr Genet 2008; 147: 375-384.

10 Henneman L, Timmermans DR, Van der Wal G: Public attitudes toward genetic testing: perceived benefits and objections. Genet Test 2006; 10: 139-145.

11 Calnan M, Montaner D, Horne R: How acceptable are innovative health-care technologies? A survey of public beliefs and attitudes in England and Wales. Soc Sci Med 2005; 60: 1937-1948.

12 Pin RR, Gutteling JM: Publieksonderzoek Genomics 2005. Enschede: Universiteit Twente, 2005

13 Aro AR, Hakonen A, Hietala M et al: Acceptance of genetic testing in a general population: age, education and gender differences. Pat Educ Couns 1997; 32 41-49.

14 Cherkas LF, Harris JM, Levinson E, Spector TD, Prainsack B: A survey of UK public interest in internet-based personal genome testing. PLoS One 2010; 5: e13473.

15 Makeeva OA, Roses AD, Puzyrev VP: An epidemiologic-based survey of public attitudes towards predictive genetic testing in Russia. Personalized Med 2010; 7: 291-300.

16 Morren M, Rijken M, Baanders AN, Bensing J: Perceived genetic knowledge, attitudes towards genetic testing, and the relationship between these among patients with a chronic disease. Pat Educ Couns 2007; 65: 197-204.

17 Molster C, Charles T, Samanek A, O'Leary P: Australian study on public knowledge of human genetics and health. Public Health Genomics 2009; 12: 84-91.

18 Henneman L, Timmermans DR, Van der Wal G: Public experiences, knowledge and expectations about medical genetics and the use of genetic information. Community Genet 2004; 7: 33-43.
19 Rose A, Peters N, Shea JA, Armstrong K: The association between knowledge and attitudes about genetic testing for cancer risk in the United States. J Health Communication 2005; 10: 309-321.

20 Jallinoja P, Aro AR: Does knowledge make a difference? The association between knowledge about genes and attitudes toward gene tests. $J$ Health Communication 2000; 5: 29-39.

21 Sanderson SC, Wardle J, Jarvis MJ, Humphries SE: Public interest in genetic testing for susceptibility to heart disease and cancer: a population-based survey in the UK. Prev Med 2004; 39: 458-464.

22 Calsbeek H, Morren M, Bensing J, Rijken M: Knowledge and attitudes towards genetic testing: a two year follow-up study in patients with asthma, diabetes mellitus and cardiovascular disease. J Genet Couns 2007; 16: 493-504.

23 Gaskell G, Allansdottir A, Allum N et al: The 2010 Eurobarometer on the life sciences. Nat Biotechnol 2011; 29: 113-114.

24 Singer E, Couper MP, Raghunathan TE, Van Hoewyk J, Antonucci TC: Trends in U.S. attitudes toward genetic testing, 1990-2004. Public Opin Q 2008; 72: 446-458.

25 Collins FS, Guttmacher AE: Genetics moves into the medical mainstream. JAMA 2001; 286: 2322-2324.

26 Burke W, Tarini B, Press NA, Evans JP: Genetic screening. Epidemiol Rev 2011; 33: 148-164.

27 Priest S, Lane T, Greenhalgh T, Hand LJ, Kramer V: Envisioning emerging nanotechnologies: a three-year panel study of South Carolina citizens. Risk Anal 2011; 31: 1718-1733.

28 Bottini M, Rosato N, Gloria F et al: Public optimism towards nanomedicine. Int J Nanomedicine 2011; 6: 3473-3485.

29 European Commission: Europeans and Biotechnology in 2010-Winds of Change?. Publications Office of the European Union 2010

30 Pijl M, Henneman L, Claassen L, Detmar SB, Nijpels G, Timmermans DR: Family history of diabetes: exploring perceptions of people at risk in the Netherlands. Prev Chronic Dis 2009; 6: A54.

31 Smerecnik CM, Mesters I, De Vries NK, De Vries H: Educating the general public about multifactorial genetic disease: applying a theory-based framework to understand current public knowledge. Genet Med 2008; 10: 251-258.

32 Ashley EA, Butte AJ, Wheeler MT et al: Clinical assessment incorporating a personal genome. Lancet 2010; 375: 1525-1535.

33 Ormond KE, Wheeler MT, Hudgins $L$ et al: Challenges in the clinical application of whole-genome sequencing. Lancet 2010; 375: 1749-1751.

34 Van Oorschot W: The Dutch welfare state: recent trends and challenges in historical perspective. Eur J Social Security 2006; 8: 57-76.

35 Schafer W, Kroneman M, Boerma W et al: The Netherlands: health system review. Health Syst Transit 2010; 12: v-xxvii 1-228.

36 Jallinoja P, Hakonen A, Aro AR et al: Attitudes towards genetic testing: analysis of contradictions. Soc Sci Med 1998; 46: 1367-1374.

37 Gutteling JM: Biotechnology in the Netherlands: controversy or consensus? Public Understanding Sci 2002; 11: 131-142. 